\title{
Laparoscopic Findings of Infertile Women at Bangabandhu Sheikh Mujib Medical University
}

\author{
Shakeela Ishrat ${ }^{1}$, Farzana Deeba ${ }^{2}$, Jesmine Banu ${ }^{3}$, Afruna Rahman Diti ${ }^{4}$ \\ ${ }^{1}$ Assistant Professor, Infertility unit, Department of Obstetrics \& Gynaecology, ${ }^{2}$ Assistant Professor, Infertility unit, Department of Obstetrics \& \\ Gynaecology, ${ }^{3}$ Associate Professor, Infertility unit, Department of Obstetrics \& Gynaecology, BSMMU ${ }^{4}$ Project Research Officer, Centre for Child and \\ Adolescent Health, ICDDR,B, Dhaka
}

\begin{abstract}
:
Background: Laparoscopy is an important component of infertility work up. It is the gold standard for evaluation of pelvic pathology and assessment of tubal patency. Objective: The objective of the study was to analyze the laparoscopic findings of infertile women presenting at Infertlity unit of Bangabandhu Sheikh Mujib Medical University. Method: We had a retrospective cross-sectional study on laparoscopic findings of 110 women. Results: Out of all patients $22.7 \%$ women had endometriosis. Various degrees of adhesion of pouch of Douglus was present in $16.4 \%$. Regarding tubal patency , 26.4\% had unilateral block and 28.2\% had bilateral block. Conclusion: A significant number of infertile women at the Infertility unit of BSMMU has tuboperitoneal disease and bilateral tubal block and ultimately need in vitro fertilization.
\end{abstract}

\section{Introduction:}

Laparoscopy enables a detailed visualization of pelvis. It allows identification of pelvic pathology and also assessment of tubal patency by chromopertubation. A free spill at the fimbrial end is reassuring but distension of tube with blockage at the fimbrial end indicates hydrosalphinx formation. Investigation of subfertility is not complete without laparoscopy. ${ }^{1}$

Subfertility is the inability of a couple to achieve conception after 1 year of unprotected intercourse. Primary infertility is the absolute state of infertility whereas secondary infertility is the same state developing after an initial phase of fertility. An abnormality in woman is responsible for $40-60 \%$ of cases of subfertility.

Bangabandhu Sheikh Mujib Medical University offers treatment to the infertile couples who cannot afford the

Address for Correspondence: Dr. Shakeela Ishrat, Assistant Professor, Infertility unit, Department of Obstetrics \& Gynaecology, Bangabandhu Shekh Mujib Medical University. Cell phone: 01729897221 expenses of private infertility centres. The infertility unit of the University offers laparoscopy to all women who have prolonged infertility, abnormal hysterosalpingogram and partners with normal semen analysis. An analysis of the laparoscopic findings of these women will help determine the frequency of tubal and pelvic factors which are more likely to require assisted reproductive techniques, procedures not available at the moment in the University. The study was undertaken to analyse the laparoscopic findings and to find out the possible female factors causing infertility in our patient population. The findings will help in the assessment of the needs of the couples we are expected to serve.

\section{Methods:}

This retrospective cross sectional study was done on patients who underwent laparoscopy in the Infertility unit, Dept of Obstetrics \& Gynaecolgy of Bangabandhu Sheikh Mujib Medical University during the year 2010. A total 110 women were taken for study. 
In the year 2010, a total of 2844 infertile couples attended the Infertility unit outdoor at BSMMU for the first time. With a prevalence of infertility at $15 \%$, the sample size was estimated to be 192 . The total number of women undergoing laparoscopy in 2010 was 110 , so was the sample size of our study with purposive sampling.

Women suffering from primary and secondary infertility, whose husbands are normospermic, duration of inferitility $>2$ yrs with no previous history of surgery or had abnormal hysterosalphingogram had laparoscopy for evaluation of infertility.

Laparosopy was performed under general anaesthesia. Pneumoperitoneum was created by direct trochar insertion and panoramic evaluation of pelvic cavity was made sequentially of ovaries, uterus,fallopian tubes, pelvic peritoneum and pouch of Douglus. Laproscopic dye test was performed with methylene blue and the findings were recorded. Diagnostic D\& C was carried out to exclude tuberculosis but the findings are not included in the present study.

Consent was taken from the department and hospital authority for analyzing available document related to laparoscopy. Data was collected in a pretested semistructured questionnaire from patients history sheet and operation theatre notes. Data was analyzed using SPSS software version 18 .

\section{Results :}

A total of 110 infertile women undergoing laparoscopy during the year 2010 was taken for study of which $70.9 \%$ $(n=78)$ had primary infertility and $29.1 \%(n=32)$ had secondary infertility. Age range of the women was $20-40$ years, mean $28 \pm 4.10$.

Table I shows the laparoscopic findings of the ovaries. Enlarged pearly white smooth surface ovaries suggestive of polycystic ovary syndrome was present in $46.4 \%$ $(\mathrm{n}=51)$. Chocolate cysts suggestive of moderate and severe endometriosis was present in $13.6 \%(n=15)$.

Table II shows the findings regarding uterine mobility and uterine anomalies. There is restricted mobility of uterus in $15.5 \%$ and fixed retroversion in $1.8 \%$. adenomyosis ( smoothly enlarged uterus with posterior bossing) was present in $13.6 \%$, fibroid uterus in $12.7 \%$.

Table III describes the endometriosis, pouch of Douglus and tubal patency. A total of 25 patients out of 110 ( $22.7 \%$ ) had endometriosis of which $3.6 \%$ was minimal and $5.5 \%$ was mild endometriosis. Pouch of Douglus was normal in most cases. Various degrees of adhesion of Pouch of Douglus was present in $16.4 \%$. Regarding tubal patency, $26.4 \%$ had unilateral block and $28.2 \%$ had bilateral block.

Table IV describes the appearance of fallopian tubes. Right and left fallopian tubes are variably affected, the left tube appearing a little more frequently abnormal than right tube (39.1\% vs $35.5 \%$ ).

Table V shows the dye test of both tubes. The dye test was negative in $30 \%$ of right tubes and $39.1 \%$ of left tubes.

Table-I

Laparoscopic findings of ovaries in infertile women $(n=110)$

\begin{tabular}{lcc}
\hline Findings & Cases & Percentage \\
\hline Normal ovaries & 46 & $41.8 \%$ \\
Enlarged, pearly white, & & \\
smooth surface & 51 & $46.5 \%$ \\
Small ovaries & 9 & $8.2 \%$ \\
Chocolate cysts & 5 & $4.5 \%$ \\
Could not be visualized & 1 & $0.9 \%$ \\
\hline
\end{tabular}


Table-II

Laparoscopic findings of uterus in infertile women

$$
(n=110)
$$

\begin{tabular}{llcc}
\hline & \multicolumn{1}{c}{ Findings } & \multicolumn{2}{c}{ Cases } \\
\hline Uterine mobility & mobile & 90 & $81.1 \%$ \\
& restricted mobility & 17 & $15.5 \%$ \\
& fixed retroverted & 2 & $1.8 \%$ \\
Uterine anomalies & fibroid & 14 & $12.7 \%$ \\
& adenomyosis & 15 & $13.6 \%$ \\
& congenital anomaly & 1 & $6.9 \%$ \\
\hline
\end{tabular}

Table-III

Laparoscopic findings of pelvis and tubal patency in infertile women $(n=110)$

\begin{tabular}{llcc}
\hline & Findings & \multicolumn{2}{c}{ Cases } \\
\hline Endometriosis & minimal & 4 & $3.6 \%$ \\
& mild & 6 & $5.5 \%$ \\
& moderate & 14 & $12.7 \%$ \\
Pouch of Douglus & severe & 1 & $0.9 \%$ \\
& normal & 92 & $83.6 \%$ \\
& flimsy adhesion & 10 & $9.1 \%$ \\
& dense adhesion & 2 & $1.8 \%$ \\
& Partially obliterated & 3 & $2.7 \%$ \\
& Densly obliterated & 2 & $1.8 \%$ \\
& Unilateral block & 29 & $26.4 \%$ \\
& Bilateral block & 31 & $28.2 \%$ \\
& Bilaterally patent & 47 & $42.7 \%$ \\
\hline
\end{tabular}

\section{Table-IV}

Laparoscopic findings of fallopian tube in infertile women $(n=110)$

\begin{tabular}{lllll}
\hline Findings & \multicolumn{2}{c}{ Left fallopian tube } & \multicolumn{2}{c}{ Right fallopian tube } \\
& Cases & Perceentage & \multicolumn{2}{c}{ CasesPercentage } \\
\hline Normal & 67 & $60.9 \%$ & 71 & $64.5 \%$ \\
Inflamed & 11 & $10 \%$ & 12 & $10.5 \%$ \\
Beaded & 23 & $20.9 \%$ & 22 & $20 \%$
\end{tabular}

/Kinking

$\begin{array}{lllll}\text { Peritubal adhesion } & 8 & 7.3 \% & 4 & 3.6 \%\end{array}$

Disturbed tubo-

ovarian relationship $19 \quad \begin{array}{llll}17.3 \% & 15 & 13.6 \%\end{array}$

\begin{tabular}{lllll} 
Hydrosalphinx & 8 & $7.3 \%$ & 10 & $9.1 \%$ \\
\hline
\end{tabular}

Table-V

Tubal patency in infertile women $(n=110)$

\begin{tabular}{lllll}
\hline Findings & \multicolumn{2}{c}{$\begin{array}{l}\text { Left fallopian tube } \\
\text { Cases }\end{array}$} & $\begin{array}{l}\text { Right fallopian tube } \\
\text { Percentage }\end{array}$ & \multicolumn{2}{c}{ CasesPercentage } \\
\hline Free spillage & 47 & $42.7 \%$ & 43 & $39.1 \%$ \\
Sluggish flow & 9 & $8.2 \%$ & 9 & $8.2 \%$ \\
$\begin{array}{l}\text { Patency after repeat } \\
\text { syringing }\end{array}$ & 1 & $9 \%$ & 2 & $1.8 \%$ \\
$\begin{array}{l}\text { Patency after } \\
\text { several syringing }\end{array}$ & 7 & $6.4 \%$ & 14 & $12.7 \%$ \\
\hline
\end{tabular}

\section{Discussion :}

The objective of the study was to analyze the laparoscopic findings of the infertile women in the Infertility unit at BSMMU. A total of 110 women was taken for the study. About ovaries , $46.4 \%$ of the women had enlarged pearly white smooth surface ovaries suggestive of polycystic ovary syndrome. These women could potentially benefit from laparoscopic ovarian drilling, a procedure rarely practiced at this center because of the risk of ovarian adhesion and premature ovarian failure. Chocolate cyst was present in only $4.5 \%$, probably because larger cysts were treated by laparotomy rather than operative laparoscopy.

About uterus, fibroid was visible in $12.7 \%$. most of them was subserous and intramural. Submucous fibroid were likely to be missed because laparoscopy was not always accompanied with hysteroscopy. Adenomyosis ( uniformly enlarged uterus with posterior bossing) was visible in $13.4 \%$. This warranted further evaluation with 
MRI for confirmation of the diagnosis of adenomyosis which has significant adverse effect on fertility.

During chromopertubation or dye test $7.4 \%$ of the left tube and $12.7 \%$ of the right tube had patency after several push. This can be ascertained that these patients had the added benefit of enhanced fertility with laparoscopy over hysterosaphingography, a procedure without anaesthesia that does not permit repeated syringing of dye.

When tubal patency is considered, unilateral block was $26.4 \%$ and bilateral block was $28.2 \%$. In a similar study carried out on 55 infertile women in Bangladesh Medical College Hospital having laparoscopy during the year 2002-2004², bilateral block was $3.64 \%$. Unilateral block was $14.56 \%$, of which right sided tubal block was $5.46 \%$ and left sided tubal block was $9.10 \%$. The findings are much lower than that of our study. In another study ${ }^{3}$ done about 20 yrs back in the same institution as our study right sided tube was blocked in $14 \%$ and left tube was blocked in $15.5 \%$,so that unilateral block was $29.5 \%$ findings more or less similar to that of our study. An study carried out on 253 infertile women in a University Teaching Hospital in Nigeria , bilateral tubal occlusion was in $38.3 \%$ and unilateral tubal occlusion in $22.1 \%$. The finding is not far different than then that of ours. ${ }^{4}$

Anwary SA et $\mathrm{al}^{5}$ carried out a study on the 73 infertile women who had laparoscopy in Bangabandhu Sheikh Mujib Medical University between February 2007 and April 2009. In that study dye test was negative in $23.3 \%$ of the right tubes and $15.1 \%$ of the left tubes, whereas in our study dye test was negative in $30 \%$ of the right tubes and $39.1 \%$ of the left tubes. The number is higher in our study probably because more women with tubal pathology are referred to this hospital now. The pouch of Douglus was obliterated in $21.8 \%$ in the previous study whereas in our study it is in $4.5 \%$. This is probably because more women are now treated earlier for pelvic infection.

\section{Conclusion :}

The study reveals that there is a high prevalence of tuboperitoneal factors among the infertile women presenting at BSMMU. Those patients with tubal disease have less success with the usual fertility treatments that we provide here at BSMMU eg ovulation induction with timed intercourse and intrauterine insemination. We are able to counsel them accordingly. The laparoscopic findings help us identify those patients with severe endometriosis and severe tubal disease including bilateral tubal block who need in vitro fertilization. The infertility wing at BSMMU should be developed into a complete tertiary level care with full facilities of assisted reproductive techniques eg in vitro fertilization. Since majority of theses couples cannot afford assisted reproductive techniques, they can be alternatively counseled for adoption or childless living.

\section{References :}

1. Desai S, Jani N. Endoscopy in infertility. In Operative Obstetrics and Gynaecology. Editors Puri R, Malhotra N. First edition 2009 Jaypee Brothers Medical Publishers New Delhi, India.

2. Deeba F, Alam ABM, Matin A, Islam MR, Ava NN, Haque N. Laparoscopic findings of ovarian and fallopian tube of subfetile women. Journal of Surgical Science 2010; 14(1):19-21.

3. Chowdhury S, Chowdhury TA. Laparoscopic assessment of tubal function in subfertility. Bangladesh J Obstet Gynaecol 1992; 17(1):9-16.

4. Ikechebelu J, Mbamara SU. Should Laparoscopy and dye test be a first line evaluation for infertile women in southeast Nigeria? Niger J Med 2011; 2094:462-5.

5. Anwary SA, Alfazzaman M, Nasreen ZA. Laparoscopic findings of subfertile female patients in a tertiary hospital. Mymensingh Med J. 2011; 20(3):391-6. 